\title{
VIRULENCE AND RESISTANCE PROFILE OF STAPHYLOCOCCUS AUREUS ISOLATED FROM FOOD
}

\author{
A. Castro, C. Palhau, S. Cunha, S. Camarinha, J. Silva and P. Teixeira* \\ Universidade Católica Portuguesa, CBQF - Centro de Biotecnologia e Química Fina - Laboratório Associado, \\ Escola Superior de Biotecnologia, Rua Arquiteto Lobão Vital, Apartado 2511, 4202-401 Porto. Portugal
}

(Received: 7 September 2016; accepted: 14 November 2016)

Staphylococcus aureus is considered a global community and health care pathogen responsible for staphylococcal food poisoning. The aim of this study was to characterize several isolates of $S$. aureus recovered from different food products concerning enterotoxin genes and other virulence factors including antimicrobial resistance. In 2009, a total of 78 coagulase-positive staphylococci from 1454 food samples were identified to species level; 73 were confirmed as $S$. aureus. Of the $S$. aureus isolates $5.5 \%$ were resistant to oxacillin, $52.0 \%$ showed resistance to erythromycin, and $45.2 \%$ to tetracycline. Multidrug resistance was observed in $33.3 \%$ of the isolates (resistance to three or more antibiotics of different classes). SCCmec types IV and V were detected among methicillin-resistant S. aureus (MRSA). One MRSA isolate was $p v l$ positive. The $52.0 \%$ of food isolates were shown to be enterotoxigenic; egc $(63.0 \%)$, secbov $(44.7 \%)$ were the main detected SEs. tst gene was also detected in food isolates. The present work demonstrates the presence of virulent $S$. aureus collected in 2009 in foods.

Keywords: Staphylococcus aureus food isolates, MRSA, SEs, antibiotic resistance

Staphylococcus aureus is an extraordinarily versatile pathogen responsible for staphylococcal food poisoning, hospital- and community-acquired infections as well as for the toxic shock syndrome (Song et al., 2015).

Staphylococcus aureus can be present in different foods such as raw milk and dairy products (JAMALI et al., 2015), fishery products (VÁzQUEZ-SÁNCHEZ et al., 2012), meat products (Bortolaia et al., 2016) among others. Staphylococcal food poisoning has been reported worldwide and is associated with oral intake of enterotoxins present in foods (JoHLER et al., 2015). Staphylococcal toxins were responsible for $7.5 \%$ of the total foodborne outbreaks reported to EFSA in 2014 (EFSA-ECDC, 2015a).

Staphylococcal enterotoxins are represented by a group of thermostable gastrointestinal protease-tolerant single chain exoproteins; at least 23 different SEs/SEls have been reported (GrumAnN et al., 2014). Another toxin, TSST-1, the toxic shock staphylococcal toxin lacks emetic activity and is known to be responsible for toxic shock syndrome (Отто, 2014). Other virulence factors, such as the presence of PVL (Panton-Valentine Leukocidin) and hemolysin- $\alpha$, exfoliative toxins, thermonuclease, hyaluronidase, and lipases, are involved in tissue invasion of the host cells by S. aureus (Grumann et al., 2014).

Antibiotics are widely used not only in human but also in animal husbandry and other agricultural activities (KLUYTMANS, 2010). The occurrence of multi-resistant strains in foods has been increasing; contaminated food is considered an important vehicle for S. aureus

* To whom correspondence should be addressed.
Phone: +351 22558 0001; fax: +351 22509 0351; e-mail: pcteixeira@porto.ucp.pt

0139-3006 @ 2017 Akadémiai Kiadó, Budapest 
antimicrobial resistance (EFSA-ECDC, 2015b). On the other hand, methicillin-resistant $S$. aureus (MRSA) strains are emerging in foods (PARISI et al., 2016).

The purpose of this study was to characterize $S$. aureus strains previously collected from several food products regarding their resistance to antibiotics and virulence factors.

\section{Materials and methods}

During 2009, seventy-eight presumptive colonies of coagulase-positive staphylococci were collected in routine analysis from several food companies (1454 food samples) in a microbiological lab (CINATE, Porto). Confirmation and presumptive identification of $S$. aureus were performed by Gram-staining, presence of catalase and coagulase, growth on Mannitol Salt Agar (Pronadisa, Spain). DNAse activity on DNase agar (Pronadisa) and thermostable DNAse activity were also detected according to CASTRO and co-workers (2016). Presumptive S. aureus isolates were thereafter stored in cryovials at $-80^{\circ} \mathrm{C}$ in Tryptone Soy Broth (TSB, Pronadisa) plus 30\% (v/v) of glycerol for further characterisation. All assays were performed as previously presented by CASTRO and co-workers (2016) including the identification to species level, namely multiplex PCR with $16 \mathrm{~S}$ rRNA and nuc and the detection of MRSA strains with mecA gene. Antibiotic susceptibility testing and detection of enterotoxin genes were determined by agar dilution and PCR, respectively. Detection of Panton-Valentine leucocidin genes was performed only to MRSA strains by PCR. Finally, SCCmec typing of MRSA was performed as described by BoYE and co-workers (2007). Control strains for five types of SCCmec were kindly supplied by Prof. Keiichi Hiramatsu (Juntendo University, Tokyo, Japan: Type I (NCTC 10442), Type II (N315), Type III (85/2082), Type IV (JCSC 4744) and Type V (Wis)).

\section{Results and discussion}

\subsection{S. aureus isolates and mecA gene}

Among the 1454 food samples, seventy-eight samples were positive for the presence of presumptive colonies of coagulase-positive staphylococci. Of those, 73 isolates were confirmed to be $S$. aureus (nuc + and $16 \mathrm{~S}$ rRNA+ detected simultaneously). S. aureus isolates were recovered from raw meat $(\mathrm{n}=3)$, raw fish $(\mathrm{n}=10)$, fermented and cured meat products $(n=5)$, cheese $(n=8)$, milk $(n=14)$, pastry $(n=7)$, bakery $(n=2)$, seafood $(n=3)$, ready-to-eat $(\mathrm{n}=19)$, and vegetables $(\mathrm{n}=2)$. S. aureus has already been isolated in similar products, namely: meat (HADJIRIN et al., 2015), milk and raw-milk products (JAMALI et al., 2015; CARFORA et al., 2016), fish products (VÁzquez-SÁncheZ et al., 2012), retail food products (WANG et al., 2014) and ready-to-eat food (Li et al., 2015). Of the food isolates 5.5\% (4/73) were classified as MRSA as the gene mecA was detected; one strain recovered from a fermented meat product, two from ready-to-eat and one from a pastry product. The occurrence of MRSA strains in food samples varies between the food product and the place of isolation. Recently, JAMALI and co-workers (2015) detected $16.2 \%$ of MRSA strains in milk and dairy products in Iran. In Italy, CARFORA and co-workers (2016) demonstrated that 5.6\% of MRSA strains were present in food from retail meat (pork and beef) in the USA. Of MRSA strains $1.4 \%$ were detected in ready-to-eat foods (WANG et al., 2014). No MRSA strains were reported on 
powdered infant formula in China (WANG et al., 2014) and fishery products in Spain (VÁzQuezSÁNCHEZ et al., 2012).

\subsection{Antimicrobial resistance}

High resistance to antibiotics was detected among the S. aureus food isolates: $83.6 \%, 90.4 \%$, $52.0 \%$, and $45.2 \%$ with respect to penicillin, ampicillin, erythromycin, and tetracycline (Table 1). All isolates were sensitive to vancomycin, gentamicin, and nitrofurantoin. It is globally accepted that antibiotic resistance in food isolates is due to the widespread usage of antibiotics (KLUYTMAnS, 2010).

Table 1. Antimicrobial susceptibility of $S$. aureus isolates

\begin{tabular}{lccc}
\hline Antibiotic & Sensitive & Intermediate & Resistant \\
& $\mathrm{N}(\%)$ & $\mathrm{N}(\%)$ & $\mathrm{N}(\%)$ \\
\hline Penicillin & $12(16.4)$ & $*$ & $61(83.6)$ \\
Ampicillin & $7(9.6)$ & $*$ & $66(90.4)$ \\
Oxacillin & $69(94.5)$ & $*$ & $4(5.5)$ \\
Chloramphenicol & $21(28.8)$ & $51(69.8)$ & $1(1.4)$ \\
Ciprofloxacin & $58(79.5)$ & $11(15.0)$ & $4(5.5)$ \\
Erythromycin & $25(34.2)$ & $10(13.7)$ & $38(52.0)$ \\
Gentamicin & $73(100)$ & $0(0.0)$ & $0(0.0)$ \\
Rifampin & $71(97.3)$ & $0(0.0)$ & $2(2.7)$ \\
Vancomycin & $73(100)$ & $0(0.0)$ & $0(0.0)$ \\
Nitrofurantoin & $73(100)$ & $0(0.0)$ & $0(0.0)$ \\
Tetracycline & $36(49.3)$ & $4(5.5)$ & $33(45.2)$ \\
\hline
\end{tabular}

$\mathrm{N}$ : number of isolates; *: Antibiotic with no described value for the intermediate MIC

Of the S. aureus isolates resistant to oxacillin (5.5\%), only one was mecA positive (isolate 709) showing a MIC of $32 \mu \mathrm{g} \mathrm{ml}^{-1}$. The other three MRSA strains did not show oxacillin resistance beside the presence of gene mecA. Three other isolates (mecA negative strains) showed to be borderline oxacillin-resistant $S$. aureus strains (MICs varying from 1 to $8 \mu \mathrm{g} \mathrm{ml}^{-1}$ ). These kinds of isolates have already been detected in foods (BYSTRÓN et al., 2010). Of S. aureus isolates $33.3 \%$ were multi-resistant (resistant to $\geq 3$ antibiotics of different classes); $30.1 \%(22 / 73)$ and $3.2 \%(2 / 73)$ were resistant to three and four antibiotics, respectively. Among food isolates only one strain was susceptible to all the eleven antibiotics investigated (data not shown).

\subsection{MRSA characterization}

The detection of MRSA is based usually (with exception of $m e c C$ ) on the presence of mecA gene in S. aureus. All MRSA were resistant to beta-lactams as an inherent characteristic due to presence of mecA gene (Table 2). The location of mecA gene is within the large chromosomal element known as the SCCmec (WATKINS et al., 2012). Only isolate 704 was nontypeable by SCCmec typing. The other MRSA isolates presented SCCmec types IV and V (Table 2). 
Generally, these SCCmec types are the most prevalent types in food; MRSA isolates SCCmec type IV were found in hamburgers in Spain (ArGuDín et al., 2012) and type V in raw meats in the UK (HADJIRIN et al., 2015).

Table 2. MRSA strains collected from food samples

\begin{tabular}{lccccc}
\hline Isolate & Origin & Resistance profile & SEs genes & SCCmec type & $p v l$ \\
\hline 301 & Fermented meat product & Pen, Amp, Eri & secbov & IV & + \\
528 & Ready-to-eat & Pen, Amp, Eri & secbov & V & - \\
704 & Pastry & Pen, Amp & seg, sei & - & - \\
709 & Ready-to-eat & Pen, Amp, Eri, Tetra, Oxa & - & V & - \\
\hline
\end{tabular}

Pen: Penicillin; Amp: Ampicillin; Eri: Erythromycin; Tetra: Tetracycline; Oxa: Oxacillin

\subsection{Virulence factors}

2.4.1. Enterotoxin genes detection. Staphylococcal food poisoning (SFP) results from the consumption of foods containing sufficient amounts of (one or more) enterotoxins (SE). Not all strains of $S$. aureus were enterotoxigenic; $52.0 \%$ presented at least one of the tested enterotoxin (38/73) and $13 \mathrm{SEs} / \mathrm{TSST}$ genes arrangements were found among food isolates $52.6 \%(20 / 38)$ that carried three or more SEs/tst genes (Table 3). Of methicillin-sensitive $S$. aureus (MSSA) 90.6\% presented more than one SE gene (data not shown). The percentage of MSSA isolates harbouring two, three, four, and five SEs/tst genes were $34.4 \%, 12.5 \%$, $31.3 \%$, and $9.4 \%$, respectively (data not shown). Moreover, one MSSA isolated from milk presented seven SEs genes. In contrast, MRSA strains showed lower presence of enterotoxin genes (Table 2). In agreement with previous findings (ArGUDín et al. 2012), egc was the most prevalent (63.0\%). secbov was the most prevalent classical enterotoxin gene (44.7\%). An outbreak due to egc has already been described (JOHLER et al., 2015). tst gene, the marker for TSST-1 (Staphylococcal Toxic Shock Syndrome) was detected (associated with others SEs) in $21.0 \%$ of the isolates. Similar results were obtained by ARGUDín and co-workers (2012) and AliBAYOV and co-workers (2014), namely 25.8 and 30\%, respectively. Absence of tst genes has already been reported by Pu and co-workers (2011) for retail meats in the USA. Toxic shock syndrome toxin (TSST) is responsible for TSS, characterized by high fever, rash, desquamation, vomiting, diarrhoea, and hypotension, frequently resulting in multiple organ failure (GrumANn et al., 2014). SEs, as superantigens (SAgs), selectively activate a vast number of $\mathrm{T}$ cells and interfere with intestine function and typically cause emesis and diarrhoea (Отто, 2014). SEs possess extraordinary stability to denaturing conditions, such as heat and low $\mathrm{pH}$, and resistance to most proteolytic enzymes, such as pepsin or trypsin (Grumann et al., 2014).

2.4.2. PVL genes detection and haemolysins, Another virulence determinant, PVLencoding genes (lukS-PV and lukF-PV), was investigated only in the case of MRSA strains. PVL-like staphylococcal enterotoxins are $S$. aureus virulence determinants that are widely distributed in many European countries, and it is possible to recover S. aureus isolates with PVL from clinical, animal, and food sources (Verkade \& Kluytmans, 2014; Hu et al., 2015). PVL positive MRSA isolates had been detected in some animals (pigs, poultry, cattle; 
Verkade \& Kluytmans, 2014) and in foods (i.e. in meat in the United States and in raw and processed food commodities in Shanghai: Hanson and co-workers (2011) and Song and coworkers (2015) respectively). The data in the literature concerning food isolates and pvl is scarce. Most of the studies concerning this virulence factor were performed with clinical isolates. In the present study, one MRSA isolated from a Portuguese traditional fermented meat product was detected. To author's knowledge there are no reports concerning the detection of pvl genes in S. aureus collected from food products in Portugal. PVL is a cytotoxin that causes leukocyte destruction and tissue necrosis (Watkins et al., 2012) associated with severe skin and soft tissue infection and necrotizing pneumonia (LinA et al., 1999). The presence of $p v l$ genes represents an increment of virulence of MRSA food isolates.

\begin{tabular}{lc} 
Table 3. Distribution of enterotoxins among Staphylococcus aureus \\
\hline Enterotoxin genes profile & $\mathrm{N}(\%)$ \\
\hline Secbov & $5(13.2)$ \\
seg, sei & $9(23.7)$ \\
secbov, seg, sei & $4(10.5)$ \\
secbov, seg, sei, tst & $3(7.9)$ \\
secbov, tst & $4(10.5)$ \\
seh, seg, sei & $3(7.9)$ \\
seh, sea, seg, sei & $4(10.5)$ \\
sea, sej, seb, seg, sei & $1(2.6)$ \\
sej, seb, sed, seg, sei & $1(2.6)$ \\
sec, sej, sed, seg, sei & $1(2.6)$ \\
seb, sed, seg, sei & $1(2.6)$ \\
secbov, seh, sea, sej, sed, & $1(2.6)$ \\
seg, sei & \\
sec, seg, sei, tst & $1(2.6)$ \\
\hline
\end{tabular}

$\mathrm{N}$ : number of isolates

Hla ( $\alpha$-haemolysin) is probably the best-known toxin of $S$. aureus with pore-forming and pro-inflammatory properties (Отто, 2014). It is lytic to red blood cells and a series of leukocytes, but not neutrophils (Отто, 2014). In the present study, Hla was present in $6.9 \%$ of S. aureus isolates. Hlg ( $\mathrm{\gamma}$-haemolysins) contrary to PVL is inflammatory but not necrotic in the rabbit skin model and is produced by more than $99 \%$ of S. aureus clinical strains (LiNA et al., 1999). In contrast to our results (presence in $17.8 \%$ of S. aureus isolates) on retail foods in China none of S. aureus isolates had hlg gene (Li et al. 2015).

\section{Conclusions}

S. aureus is routinely detected and/or enumerated in a wide variety of ready-to-eat foods as part of preventive approach and microbiological safety checks based on hazard analysis and critical control point principles. In the present study, the characterization of S. aureus isolated 
from food samples was evaluated. Globally, it was demonstrated that food might be an important source of dissemination of antibiotic resistant and virulent strains of $S$. aureus. Since the isolates presented here are from the year 2009, it would be interesting to collect and study more recent isolates to determine whether the occurrence of MRSA and the pathogenicity of $S$. aureus vary from year-to-year.

This work was supported by the National Funds from FCT-Fundação para a Ciência e a Tecnologia through project UID/Multi/50016/2013. Financial support for author Ana Castro was provided by FCT through doctoral fellowship $\mathrm{BD} / 39315 / 2007$

\section{References}

Alibayov, B., Zdenkova, K., Sykorova, H. \& Demnerova, K. (2014): Molecular analysis of Staphylococcus aureus pathogenicity islands (SaPI) and their superantigens combination of food samples. J. Microbiol. Meth., 107, 197-204.

Argudín, M.A., Mendoza, M.C., Gonzélez-Hevia, M.A., Bances, M., Guerra, B. \& Rodicio, M.R. (2012): Genotypes, exotoxin gene content, and antimicrobial resistance of Staphylococcus aureus strains recovered from foods and food handlers. Appl. Environ. Microb., 78, 2930-2935.

Boye, K., Bartels, M.D., Andersen, I.S., Moller, J.A. \& Westh, H. (2007): A new multiplex PCR for easy screening of methicillin-resistant Staphylococcus aureus SCCmec types I-V. Clin. Microbiol. Infec., 13, 725-727.

Bortolaia, V., Espinosa-Gondora, C. \& Guardabassi, L. (2016): Human health risks associated with antimicrobialresistant enterococci and Staphylococcus aureus on poultry meat. Clin. Microbiol. Infec., 22, 130-140.

Bystrón, J., Podkowik, M., Korzekwa, K., Lis, E., Molenda, J. \& Bania, J. (2010): Characterization of borderline oxacillin-resistant Staphylococcus aureus isolated from food of animal origin. J. Food Protect., 73, 13251327.

Carfora, V., Giacinti, G., Sagrafoli, D., Marri, N., Giangolini, G., Alba, P., Feltrin, F., Sorbara, L., Amoruso, R., Caprioli, A., Amatiste, S. \& Battisti, A. (2016): Methicillin-resistant and methicillin-susceptible Staphylococcus aureus in dairy sheep and in-contact humans: An intra-farm study. J. Dairy Sci., 99, 42514258 .

Castro, A., Komora, N. Ferreira, V. Lira, A. Mota, M. Silva, J. \& Teixeira, P. (2016): Prevalence of Staphylococcus aureus from nares and hands on healthcare professionals in a Portuguese hospital. J. Appl. Microbiol., 121, $831-839$.

EFSA-ECDC (2015a): The European Union summary report on trends and sources of zoonoses, zoonotic agents and food-borne outbreaks in 2014. EFSA Journal, 13(12), 4329.

EFSA-ECDC (2015b): EU Summary Report on antimicrobial resistance in zoonotic and indicator bacteria from humans, animals and food in 2013. EFSA Journal, 13(2), 4036.

Grumann, D., NüBel, U. \& BröKer, B.M. (2014): Staphylococcus aureus toxins - Their functions and genetics. Infect. Genet. Evol., 21, 583-592.

Hadjirin, N.F., Lay, E.M., Paterson, G.K., Harrison, E.M., Peacock, S.J., Parkhill, J., Zadoks, R.N. \& Holmes, M.A. (2015): Detection of livestock-associated methicillin-resistant Staphylococcus aureus CC398 in retail pork, United Kingdom, February 2015. Euro Surveill., 20, 21156.

Hanson, B.M., Dressler, A.E., Harper, A.L., Scheibel, R.P., Wardyn, S.E., Roberts, L.K., Kroeger, J.S. \& Smith, T.C. (2011): Prevalence of Staphylococcus aureus and methicillin-resistant Staphylococcus aureus (MRSA) on retail meat in Iowa. J. Infect. Public Health, 4, 169-174.

Hu, Q., Cheng, H., Yuan, W., Zeng, F., Shang, W., Tang, D., Xue, W., Fu, J., Zhou, R., Zhu, J. Yang, J., Hu, Z., Yuan, J., Zhang, X., Rao, Q., Li, S., Chen, Z., Hu, X., Wu, X. \& Rao, X. (2015): Panton-Valentine Leukocidin (PVL)-positive health care-associated methicillin-resistant Staphylococcus aureus isolates are associated with skin and soft tissue infections and colonized mainly by infective PVL-encoding bacteriophages. J. Clin. Microbiol., 53(1), 67-72.

Jamali, H., Paydar, M., Radmehr, B., Ismail, S. \& Dadrasnia, A. (2015): Prevalence and antimicrobial resistance of Staphylococcus aureus isolated from raw milk and dairy products. Food Control, 54, 383-388. 
Johler, S., Giannini, P., Jermini, M., Hummerjohann, J., Baumgartner A. \& Stephan, R. (2015): Further evidence for staphylococcal food poisoning outbreaks caused by egc-encoded enterotoxins. Toxins, 7, 997-1004.

Kluytmans, J.A.J.W. (2010): Methicillin-resistant Staphylococcus aureus in food products: cause for concern or case for complacency? Clin. Microbiol. Infec., 16, 11-15.

Li, G., Wu, C., Wang, X. \& Meng, J. (2015): Prevalence and characterization of methicillin susceptible Staphylococcus aureus ST398 isolates from retail foods. Int. J. Food Microbiol., 196, 94-97.

Lina, G., Piémont, Y., Godail-Gamot, F., Bes, M., Peter, M.-O., Gauduchon, V., Vandenesch, F. \& Etienne J. (1999): Involvement of Panton-Valentine leukocidin-producing Staphylococcus aureus in primary skin infections and pneumonia. Clin. Infect. Dis., 29, 1128-1132.

Отто, M. (2014): Staphylococcus aureus toxins. Curr. Opin. Microbiol., 17, 32-37.

Parisi, A., Caruso, M., Normanno, G., Latorre, L., Sottili, R., Miccolupo, A., Fraccalvieri, R. \& Santagada, G. (2016): Prevalence, antimicrobial susceptibility and molecular typing of methicillin-resistant Staphylococcus aureus (MRSA) in bulk tank milk from southern Italy. Food Microbiol., 58, 36-42.

Pu, S., Wang, F. \& GE, B. (2011): Characterization of toxin genes and antimicrobial susceptibility of Staphylococcus aureus isolates from Louisiana retail meats. Foodborne Pathog. Dis., 8, 299-306.

Song, M., Bai, Y., Xu, J., Carter, M.Q., Shi, C. \& Shi, X. (2015): Genetic diversity and virulence potential of Staphylococcus aureus isolates from raw and processed food commodities in Shanghai. Int. J. Food Microbiol., 195, 1-8.

Vázquez-Sánchez, D., López-Cabo, M., SaÁ-Ibusquiza, P. \& Rodríguez-Herrera, J.J. (2012): Incidence and characterization of Staphylococcus aureus in fishery products marketed in Galicia (Northwest Spain). Int. J. Food Microbiol., 157, 286-296.

Verkade, E. \& Kluytmans, J. (2014): Livestock-associated Staphylococcus aureus CC398: animal reservoirs and human infections. Infect. Genet. Evol., 21, 523-530.

WANG, X., Li, G., XIA, X., YAnG, B., XI, M. \& MEnG, J. (2014): Antimicrobial susceptibility and molecular typing of methicillin-resistant Staphylococcus aureus in retail foods in Shaanxi, China. Foodborne Pathog. Dis., 11, 281-286.

Watkins, R.R., David, M.Z. \& SAlATA, R.A. (2012): Current concepts on the virulence mechanisms of methicillinresistant Staphylococcus aureus. J. Medical Microbiol., 61, 1179-1193. 